\title{
Determinantes da lealdade online em sites de alojamento: um estudo comparativo do comportamento do consumidor português e brasileiro
}

\author{
Determinants of Online Loyalty on Hosting Sites: A Comparative Study of Portuguese and \\ Brazilian Consumer Behavior
}
Determinantes de la lealtad online en sitios web de alojamiento: un estudio comparativo del comportamiento del consumidor portugués y brasileño

Pâmela Mossmann de Aguiar ${ }^{1}$ Cristela Maia Bairrada ${ }^{2}$ Arnaldo Fernandes Matos Coelho ${ }^{3}$

Este artigo foi recebido em 06 de setembro de 2019 e aprovado em 01 de julho de 2020

\begin{abstract}
Resumo: Tendo em conta o ambiente digital onde atualmente vivemos, este trabalho de investigação objetiva estudar os determinantes da lealdade online, mais especificamente nos sites de reserva de alojamento. Este trabalho visou abarcar um número maior de possíveis antecedentes da lealdade online, tanto de cunho cognitivo (como o valor utilitário, o valor percebido, o boca-a-boca online), quanto afetivo (como o valor hedônico, a percepção de diversão, a aprendizagem). Além disso, propõe-se a analisar se as diferenças culturais entre os brasileiros e os portugueses afetam a lealdade online e as relações que se estabelecem entre esta variável e os seus antecedentes, pelo que a amostra final é constituída por 482 indivíduos (227 brasileiros e 255 portugueses). A análise dos dados, feita por meio da Modelagem de Equações Estruturais (MEE), mostrou que as diferenças culturais influenciam na formação da lealdade online. Também revelou que, por um lado, a qualidade online, a percepção de diversão, a satisfação online e o valor utilitário apresentaram-se como importantes antecedentes da lealdade online. Por outro lado, verificou-se que o valor hedônico apareceu como um possível influenciador que merece atenção e maior investigação.
\end{abstract}

Palavras-chave: Diferenças culturais. Lealdade online. Sites de reserva de alojamento.

\begin{abstract}
Taking into consideration the digital world where we currently live, this research aims to study the determinants of online loyalty, more specifically in the accommodation booking sites. This work aimed to cover a larger number of possible antecedents of online loyalty, both cognitive (such as utilitarian value, perceived value, word of mouth online), and affective (such as hedonic value, perception of fun, the Learn). In addition, it is proposed to analyze whether cultural differences between Brazilians and Portuguese affect online loyalty and the relationships established between this variable and its antecedents, so the final sample consists of 482 individuals (227 Brazilians and 255 Portuguese). Data analysis, using the Structural Equations Model (SEM), showed that cultural differences influence the formation of online loyalty. It also revealed that online quality, fun perception, online satisfaction, and value for money have all turned out to be important precedents for online loyalty. On the other hand, it was verified that the hedonic value appeared as a possible influencer, which deserves attention and further investigation.
\end{abstract}

Key words: Cultural differences. E-Loyalty. Accommodation booking sites.

Resumen: Tiendo en cuenta el ambiente digital adónde vivimos actualmente, este trabajo de investigación objetiva estudiar los determinantes de la lealtad online, más específicamente en los sitios web de reserva de alojamiento. Este trabajo pretendió abarcar un número mayor de posibles antecedentes de la lealtad online, tanto carácter cognitivo (cómo el valor utilitario, el valor percibido, lo boca a boca online), cuánto afectivo (cómo el valor hedónico, la percepción de diversión, el aprendizaje). Además, se propone analizar si las diferencias culturales entre los brasileños e los portugueses afectan la lealtad online y las relaciones que se establecen entre esta variable y sus antecedentes, por lo que la muestra final es constituida por 482 individuos (227 brasileños y 255 portugueses).

\footnotetext{
${ }^{1}$ Formação/curso: Mestre em Marketing. Instituição: Faculdade de Economia da Universidade de Coimbra - FEUC, Coimbra, Portugal. Email: pamossmann@gmail.com

${ }^{2}$ Formação/curso: Professora Auxiliar e Doutora em Gestão de Empresas (especialização em Marketing), Instituição: Faculdade de Economia da Universidade de Coimbra - FEUC, Coimbra, Portugal. E-mail: cristela.bairrada@ gmail.com

${ }^{3}$ Formação/curso: Professor Auxiliar. Instituição: Faculdade de Economia da Universidade de Coimbra - FEUC, Coimbra, Portugal. E-mail: coelho1963@hotmail.com
} 
DETERMINANTES DA LEALDADE ONLINE EM

SITES DE ALOJAMENTO: UM ESTUDO

COMPARATIVO DO COMPORTAMENTO DO

CONSUMIDOR PORTUGUÊS E BRASILEIRO
Pâmela Mossmann de Aguiar Cristela Maia Bairrada Arnaldo Fernandes Matos Coelho

El análisis de los datos, hecha a través del Moldeado de las Ecuaciones Estructurales (MEE), mostró que las diferencias culturales influencian en la formación de la lealtad online. También reveló que la calidad online, la percepción de diversión, la satisfacción online y el valor utilitario se presentaron cómo importantes antecedentes de la lealtad online. Por otro lado, se verifico que el valor hedónico apareció cómo una posible influencia, lo cual merece atención y más investigación.

Palabras Clave: Diferencias culturales. Lealtad Online. Sitios web de reserva de alojamiento.

\section{Introdução}

A Internet é um elemento cada vez mais presente e importante na nossa vida. Uma empresa que não exista na Web pode enfrentar sérias dificuldades, na medida em que deixa de ser lembrada pelos consumidores, além de passar a ideia de não ser confiável, já que atualmente é habitual pesquisarmos sobre uma empresa, os seus produtos e serviços na Internet antes de decidirmos pela sua aquisição (NIELSEN, 2016). Esta realidade não é diferente para os sites de reserva de alojamento, onde a Internet tornou-se uma importante ferramenta de negócios (MOUAKKET; AL-HAWARI, 2012).

A relação entre a satisfação online, a confiança online e a lealdade online é um importante tópico da compra online e do comércio eletrônico, visto que o comprometimento de longo prazo do consumidor - ou a sua lealdade - traz lucros a longo prazo para os vendedores online (REICHHELD; SCHEFTER, 2000). No setor do turismo, muitos autores analisam a lealdade online, principalmente em relação aos elementos associados aos sites para a reserva de alojamentos em hotéis e a compra de passagens aéreas (LEE; CRANAGE, 2011; PONTE; TRUJILLO; RODRÍGUEZ, 2015; MOUAKKET; AL-HAWARI, 2012). Esses estudos avaliam a relação da lealdade online com outros construtos no âmbito do turismo.

Para além disso, os elementos culturais também podem influenciar a propensão à lealdade online. Haryanto, Moutinho e Coelho (2016) apontam características culturais passíveis de explicar possíveis diferenças no ato de consumir. Um fator cultural importante de ser ressaltado diz respeito ao individualismo e ao evitamento da incerteza. Indivíduos que apresentam maior evitamento da incerteza são mais propensos a serem leais a uma marca, pelo fato de que tendem a se arriscar menos, atitude que leva ao menor desejo de trocar de marca. Também as pessoas que apresentam maior propensão ao individualismo são menos prováveis de trocar de marca (HARYANTO; MOUTINHO; COELHO, 2016).

Lins e Poeschl (2016) detectaram diferenças nas representações de compra de adolescentes portugueses e brasileiros, devido às diferenças culturais dos dois países. Os meninos portugueses evocam muito mais os produtos masculinos, enquanto as meninas brasileiras o fazem em relação aos produtos femininos, o que pode refletir como a identidade de gênero expressa-se nesses países. Além disso, os adolescentes portugueses deram mais ênfase aos aspectos cognitivos (gastar, adquirir, preço, necessidade, dinheiro, usar), enquanto os adolescentes brasileiros preferiram aspectos ambientais (loja,

Observatório de Inovação do Turismo - Revista Acadêmica

Vol. XIV, $\mathrm{n}^{\circ} 3$, dezembro - 2020 
DETERMINANTES DA LEALDADE ONLINE EM

SITES DE ALOJAMENTO: UM ESTUDO

COMPARATIVO DO COMPORTAMENTO DO

CONSUMIDOR PORTUGUÊS E BRASILEIRO
Pâmela Mossmann de Aguiar Cristela Maia Bairrada Arnaldo Fernandes Matos Coelho

pais, dinheiro, consumismo, cartão de crédito, moda, marca) e emocionais (prazer, satisfação, felicidade, comprar, vaidade). Os autores concluíram que os adolescentes portugueses tendem a incluir as pectos mais negativos relacionados ao seu comportamento de compra do que os adolescentes brasileiros. Esta associação ocorre inclusive com os aspectos ambientais, que geralmente são neutros. Na verdade, de acordo com o Hofstede Insights (2020), os brasileiros tendem a ser mais individualistas que os portugueses, e o inverso acontece com a aversão ao risco onde os portugueses apresentam um valor mais elevado.

Dessa forma, o objetivo geral deste trabalho é estudar os determinantes da lealdade online para os consumidores brasileiros e portugueses. Pretende-se assim, com esta investigação, compreender como a lealdade online é formada no ambiente online, mais especificamente nos sites de reserva de alojamento. Como objetivos específicos, pretendemos: 1 . Testar a atuação dos constructos, propostos e já identificados em estudos anteriores, sobre a lealdade online; 2. Identificar e sugerir antecedentes e consequentes que ainda não foram descritos em outras investigações; 3. Avaliar o impacto da cultura na lealdade online, ao comparar o comportamento de brasileiros e portugueses quando utilizam este meio para efetuar a sua reserva de alojamento

De seguida, este trabalho de investigação encontra-se dividido em quatro seções. Depois de apresentar a Revisão da Literatura e Hipóteses será descrita a Metodologia de investigação. Na parte final deste artigo, serão apresentados os Resultados, a Discussão e as Considerações Finais.

\section{Revisão da Literatura e Hipóteses}

Nesta seção serão apresentados os conceitos dos construtos investigados neste trabalho. O objetivo é apresentar as principais relações já analisadas em outros estudos e que inspiraram as hipóteses de pesquisa propostas neste trabalho. A escolha dos construtos e a definição das hipóteses foram baseadas em mais de um modelo existente, de modo a reunir construtos bastante presentes na literatura e construtos que ainda precisam ser mais testados nas suas relações - diretas ou indiretas - com a lealdade online do consumidor.

\subsection{Lealdade online}

De acordo com Oliver (1999), a lealdade tradicional pode ser definida como um comprometimento profundamente assegurado pela recompra ou pelo consumo regular de um produto ou serviço, o qual será preferido continuamente no futuro pelo consumidor. Esse compromisso causa compras repetidas de uma mesma marca ou de um mesmo conjunto de marcas, apesar das influências

Observatório de Inovação do Turismo - Revista Acadêmica

Vol. XIV, $\mathrm{n}^{\circ} 3$, dezembro - 2020 
DETERMINANTES DA LEALDADE ONLINE EM

SITES DE ALOJAMENTO: UM ESTUDO

COMPARATIVO DO COMPORTAMENTO DO

CONSUMIDOR PORTUGUÊS E BRASILEIRO
Pâmela Mossmann de Aguiar Cristela Maia Bairrada Arnaldo Fernandes Matos Coelho

situacionais e dos esforços de marketing dos concorrentes com potencial para causar o comportamento de troca do consumidor.

Srinivasan, Anderson e Ponnavolu (2002) definem a lealdade online como uma atitude favorável em relação a um varejista online, o qual resulta num comportamento de compras repetidas. Esses autores realizaram entrevistas em profundidade com 42 pessoas e concluíram que existem oito fatores que parecem afetar a lealdade online: (1) a customização; (2) a interatividade de contatos; (3) a continuidade; (4) o cuidado/preocupação; (5) o efeito comunidade; (6) a variedade; (7) a conveniência e (8) o caráter/reputação.

Reichheld e Schefter (2000) salientam que no começo de uma relação com o consumidor online, o investimento necessário para conquistá-lo é frequentemente considerado mais alto no comércio eletrónico do que nos canais de varejo tradicionais. No entanto, nos anos futuros, o crescimento do lucro acelera a uma taxa ainda mais rápida, comparado aos consumidores dos canais de venda tradicionais. Esses autores afirmam que o aumento da retenção de clientes no meio eletrónico em $5 \%$ é capaz de aumentar os lucros entre $25 \%$ e $95 \%$.

Reichheld e Schefter (2000) referem ainda que, além de comprar mais, os clientes leais no ambiente online também encaminham frequentemente novos clientes a um fornecedor, o que proporciona outra fonte rica de lucros. Isso também ocorre no comércio tradicional, contudo a Internet amplifica este efeito, na medida em que o 'boca-a-boca eletrônico' é ainda mais rápido que o boca-aboca tradicional.

\subsubsection{A lealdade online e a intenção de troca}

Han, Kim e Hyun (2011) consideram que a intenção de troca está relacionada com a probabilidade afirmada pelo consumidor de trocar o atual fornecedor de serviço por outro. Os fatores que predispõem a dissolução da relação são diversos. Podem estar relacionados com o incumprimento de tarefas inerentes ao relacionamento (como deficiências na entrega da qualidade do serviço solicitado ou desejado pelo consumidor) ou com a diminuição do comprometimento e interesse demonstrado pela empresa na relação. Os fatores que precipitam o rompimento da relação são eventos que impelem o consumidor a tomar medidas para finalizar a relação. Eles podem ser repentinos e dramáticos ou fazer parte de uma série de eventos que levam o consumidor a mudar de fornecedor.

Yang e Peterson (2004) evidenciam que, embora os custos de mudança (um dos componentes das barreiras de intenção de troca) tenham um impacto positivo sobre a lealdade do consumidor, o seu efeito sobre a lealdade é insignificante. Ademais, as interações dos custos de mudança com a satisfação 
DETERMINANTES DA LEALDADE ONLINE EM

SITES DE ALOJAMENTO: UM ESTUDO

COMPARATIVO DO COMPORTAMENTO DO

CONSUMIDOR PORTUGUÊS E BRASILEIRO
Pâmela Mossmann de Aguiar Cristela Maia Bairrada Arnaldo Fernandes Matos Coelho

do consumidor e o valor percebido ocasionaram influências negativas e insignificantes sobre a lealdade do consumidor.

Dessa forma, propõe-se a seguinte hipótese em relação à intenção de troca:

H1: A lealdade online do consumidor está negativamente relacionada com a intenção de troca.

\subsubsection{Antecedentes da lealdade online}

\subsubsection{Confiança online}

A confiança pode ser definida como uma crença, um sentimento ou uma expectativa sobre uma empresa resultante da experiência, confiabilidade e intencionalidade do consumidor de que ela cumprirá com as obrigações estabelecidas numa troca (GANESAN, 1994; GUNDLACH; MURPHY, 1993). No ambiente online, a confiança pode ser categorizada em quatro tipos: confiança (1) no site, (2) no vendedor, (3) no iniciador da oferta, e (4) nos membros do grupo (HSU; CHUANG; HSU, 2014). Importa realçar que a confiança influencia uma série de variáveis de troca relevantes: comunicação e feedback, solução de problemas, delegação efetiva, e a aceitação de metas comuns e de compartilhamento de responsabilidade (GUNDLACH; MURPHY, 1993).

Para ganhar a lealdade dos consumidores, as empresas devem primeiro conquistar a sua confiança, visto que quando questionados sobre os atributos mais importantes para ganhar os seus negócios, a resposta número um dos consumidores foi: “um site que eu conheça e confie". Desse modo, a confiança do consumidor numa loja online pode ser definida como a confiança do consumidor diretamente na loja ou a sua lealdade à loja (JARVENPAA; TRACTINSKY; VITALE, 2000; QUELCH; KLEIN, 1996; REICHHELD; SCHEFTER, 2000).

Na sua relação com outros construtos, estudos anteriores no setor do turismo demonstraram que a confiança é um importante influenciador da intenção de compra do consumidor em sites de turismo (AGAG; EL-MASRY, 2016; CURRAS-PEREZ et al., 2017; PAPPAS, 2016; PONTE; TRUJILLO; RODRÍGUEZ, 2015). Agag e El-Masry (2016) descobriram que a confiança é um indicador chave de desempenho para empresas de viagem online, que influencia a percepção de risco, a atitude, e as intenções de compra online do consumidor de viagem. Pappas (2016) verificou que a confiança no produto e no fornecedor online influenciam quase que igualmente a intenção de compra dos consumidores de viagens.

Com base no exposto acima, a seguinte hipótese de estudo é proposta:

H2: A confiança online está positivamente relacionada com a lealdade online do consumidor.

Observatório de Inovação do Turismo - Revista Acadêmica

Vol. XIV, $\mathrm{n}^{\circ} 3$, dezembro - 2020 
DETERMINANTES DA LEALDADE ONLINE EM

SITES DE ALOJAMENTO: UM ESTUDO

COMPARATIVO DO COMPORTAMENTO DO

CONSUMIDOR PORTUGUÊS E BRASILEIRO
Pâmela Mossmann de Aguiar Cristela Maia Bairrada Arnaldo Fernandes Matos Coelho

\subsubsection{Satisfação online}

Oliver (2015) define satisfação como a resposta do contentamento do consumidor. É o julgamento de que as características de um produto/serviço, ou que o produto ou o serviço por si próprio, proporcionou (ou está a proporcionar) um nível agradável de satisfação relacionada ao consumo, incluindo níveis de satisfação abaixo ou acima do esperado pelo consumidor. O autor explica que agradável, neste caso, implica que a satisfação dê ou aumente o prazer, ou reduza a dor do consumidor.

A satisfação online pode ser explicada como o contentamento do consumidor em relação à sua experiência anterior com uma determinada empresa que está presente no ambiente digital (ANDERSON; SRINIVASAN, 2003). Anderson e Swaminathan (2011) afirmam que a satisfação do consumidor com uma empresa do comércio eletrônico tem a ver com a avaliação do consumidor das suas experiências pré e pós-compra. Caso as expectativas dos consumidores sejam cumpridas ou excedidas na experiência total de compra/serviço, há maior probabilidade de eles se sentirem satisfeitos ou inclinados a serem leais a essa empresa online e menos propensos a procurar produtos e serviços alternativos oferecidos pelos concorrentes.

De fato, estudos anteriores indicam que a satisfação online influencia positivamente a lealdade online (ANDERSON; SWAMINATHAN, 2011; CHANG; CHEN, 2009). No setor do turismo, estudos anteriores também apontam a influência positiva da satisfação online sobre a lealdade online ou intenção de recompra de sites de turismo (ALI, 2016; CURRAS-PEREZ et al., 2017; KAMAL et al., 2018; KIM; PARK, 2016; LUO et al., 2019; PEREIRA; SALGUEIRO; RITA, 2016). A interatividade dos sites de turismo pode atrair e reter clientes, e também pode melhorar a experiência do consumidor, o que leva a uma maior satisfação e intenção de recompra (ALI, 2016; LUO et al., 2019). Além disso, a capacidade de resposta do site de turismo afeta positivamente a experiência perceptiva e emocional dos consumidores, o que influencia positivamente ainda mais a sua satisfação, o que pode levar à lealdade do consumidor (LUO et al., 2019). Em Portugal, Pereira, Salgueiro e Rita (2016) descobriram que a imagem do site, e o conhecimento do site desempenha um papel significante na satisfação online do consumidor, e, indiretamente, melhora a sua lealdade online.

Relativamente há uma relação entre satisfação online e confiança online no contexto dos sites de serviços de viagens, Curras-Perez et al. (2017) encontraram que a satisfação online exerce uma influência positiva sobre a confiança online.

Face ao exposto, propomos que:

H3: A satisfação online do consumidor tem uma influência positiva sobre a lealdade online do consumidor.

Observatório de Inovação do Turismo - Revista Acadêmica

Vol. XIV, $\mathrm{n}^{\circ} 3$, dezembro - 2020 
DETERMINANTES DA LEALDADE ONLINE EM

SITES DE ALOJAMENTO: UM ESTUDO

COMPARATIVO DO COMPORTAMENTO DO

CONSUMIDOR PORTUGUÊS E BRASILEIRO
Pâmela Mossmann de Aguiar Cristela Maia Bairrada Arnaldo Fernandes Matos Coelho

H4: A satisfação online do consumidor tem uma influência positiva sobre a confiança online do consumidor.

\subsubsection{Valor hedônico}

O consumo hedônico relaciona-se com os aspectos multissensoriais, fantásticos e emotivos da experiência de uma pessoa com os produtos (HIRSCHMAN; HOLBROOK, 1982). A motivação hedônica está associada à experiência de compra em si e refere-se àqueles comportamentos de consumo que buscam a felicidade, a fantasia, o despertar, a sensualidade e a diversão. O processo de compra é divertido para os consumidores hedônicos, razão pela qual amam o ato de fazer compras (TO; LIAO; LIN, 2007).

No setor do turismo, estudos já mostraram que o valor hedônico exerce um efeito positivo sobre a satisfação online (EL-ADLY, 2019; KAMAL et al., 2018; LEE; KIM, 2018).

Dito isso, propõe-se a seguinte hipótese de pesquisa:

H5: O valor hedônico está positivamente relacionado com a satisfação online do consumidor.

\subsubsection{Percepção de valor}

O valor percebido baseia-se na teoria da equidade, a qual sugere, numa relação de troca, que as partes envolvidas se sentirão tratadas de forma equitativa e, assim satisfeitas, se a proporção entre os seus resultados e as contribuições forem, em certo sentido, justas (BOLTON; LEMON, 1999; OLIVER; DESARBO, 1988; YANG; PETERSON, 2004). O valor percebido pelo cliente resulta de uma avaliação das recompensas relativas e dos sacrifícios associados à oferta, e a satisfação existe quando o consumidor percebe que a sua proporção de resultados-contribuições está equilibrada com a de seu parceiro (OLIVER; DESARBO, 1988) (YANG; PETERSON, 2004).

No turismo, resultados de trabalhos anteriores indicaram que o valor percebido impacta positivamente a satisfação online do consumidor (EL-ADLY, 2019; KHUONG, 2017; KIM; PARK, 2016).

Dessa forma, a hipótese sugerida é:

H6: $\mathrm{O}$ valor percebido pelo consumidor está positivamente relacionado com a sua satisfação online. 
DETERMINANTES DA LEALDADE ONLINE EM

SITES DE ALOJAMENTO: UM ESTUDO

COMPARATIVO DO COMPORTAMENTO DO

CONSUMIDOR PORTUGUÊS E BRASILEIRO
Pâmela Mossmann de Aguiar Cristela Maia Bairrada Arnaldo Fernandes Matos Coelho

\subsubsection{Valor utilitário}

O valor utilitário do consumo está associado com o ato de compra eficiente, definido como uma missão crítica, racional, decisão efetiva e orientada por objetivos, que avalia os atributos funcionais da marca e causa o mínimo de irritação aos consumidores (BATRA; AHTOLA, 1990; CHILDERS et al., 2001; JONES; REYNOLDS; ARNOLD, 2006; TO; LIAO; LIN, 2007).

To, Liao e Lin (2007) apontam variáveis como conveniência, seleção, disponibilidade de informação e economia de custos como exemplos de valores utilitários. Estes mesmos autores afirmam que a motivação utilitária tem mais influência nas intenções de procura e de compra do que a motivação hedônica. Isso ocorre porque os consumidores que navegam e compram pela Internet tendem a ser práticos e são motivados por propostas utilitárias.

Referente ao setor do turismo, pesquisas anteriores já demonstraram o efeito positivo do valor utilitário sobre a satisfação online do consumidor (KAMAL et al., 2018; LEE; KIM, 2018).

Assente no exposto acima, propõe-se a seguinte hipótese de pesquisa:

H7: O valor utilitário está positivamente relacionado com a satisfação online do consumidor.

\subsubsection{Percepção de risco online}

De acordo com Alcántara-Pilar et al. (2015), o risco percebido online pode ser definido como a sensação de insegurança e de vulnerabilidade enquanto se navega na Internet. Na realidade, a percepção de um risco baixo é um determinante essencial da intenção de compra em processos de tomada de decisão, bem como um ingrediente fundamental para as relações de longo prazo bem-sucedidas entre empresa e clientes (ALCÁNTARA-PILAR et al., 2018).

Os consumidores que têm um nível alto de risco percebido apresentam índices maiores de afeto pelo site (quando comparados com aqueles que apresentam um nível mais baixo de risco percebido) no caso de seu processo de navegação ser bem-sucedido, o que os deixa satisfeitos (ALCÁNTARA-PILAR et al., 2018). Se os consumidores reconhecem, por meio de sinais, que o vendedor online propicia segurança e proteção da privacidade em transações online, a sua percepção de incerteza e de riscos na compra online tendem a ser reduzidos.

Estudos prévios no setor do turismo mostraram que o risco online percebido tem um efeito negativo sobre a satisfação online do consumidor (CHEN et al., 2016; GHOTBABADI; FEIZ; BAHARUN, 2016) e a confiança online do consumidor (ZHANG; YANG, 2019).

Com base no apresentado acima, propõe-se as seguintes hipóteses de pesquisa: 
DETERMINANTES DA LEALDADE ONLINE EM

SITES DE ALOJAMENTO: UM ESTUDO

COMPARATIVO DO COMPORTAMENTO DO

CONSUMIDOR PORTUGUÊS E BRASILEIRO
Pâmela Mossmann de Aguiar Cristela Maia Bairrada Arnaldo Fernandes Matos Coelho

H8: O risco online percebido pelo consumidor está negativamente relacionado com a confiança online.

H9: O risco online percebido pelo consumidor está negativamente relacionado com a satisfação online.

\subsubsection{Percepção de diversão}

Quando o processo de compra online é agradável, há a percepção de diversão, que incorpora uma dimensão hedônica ao consumo Web. Os consumidores que se interessam por experiências de consumo procuram um estímulo durante a compra e veem este processo como uma tarefa divertida (BÜTTNER; FLORACK; GÖRITZ, 2013; FANG; SHAO; WEN, 2016). Além disso, perante a elevada competitividade no mercado online, os varejistas têm focado no aumento da percepção de diversão do consumidor (e em alguns casos, de excitação) para garantir níveis maiores de intenção de compra repetida (BAUER; FALK; HAMMERSCHMIDT, 2006; FANG; SHAO; WEN, 2016). Bauer, Falk e Hammerschmidt (2006) constataram que a dimensão diversão tem um forte impacto sobre a duração da relação entre consumidor e empresa, que é o maior antecedente da lucratividade do consumidor.

Trabalhos na área do turismo indicam que a percepção de diversão é um dos elementos componentes do valor hedônico. Esses elementos hedônicos são muito importantes para os sites de empresas de turismo e podem ser associados especialmente à navegação no site e às experiências de realidade virtual dos consumidores (ALBAYRAK et al., 2019; CHOI; CHOI, 2019; KIM; HALL, 2019).

Desse modo, sugere-se a seguinte hipótese de pesquisa:

H10: A percepção de diversão pelo consumidor é um dos elementos componentes do valor hedônico.

\subsubsection{Qualidade online}

A qualidade do site corresponde às avaliações dos usuários sobre a capacidade de os recursos de um site atenderem às suas necessidades e reflete a excelência geral do site (CHANG; CHEN, 2008; LU; YEUNG, 1998; NIELSEN, 1993; 1995 apud LU; YEUNG, 1998). Desta forma, pode-se afirmar que a qualidade online tem em conta aspectos como o Cumprimento/confiabilidade, o Design do site, a Segurança/privacidade e a Agilidade de resposta.

Os resultados de Kim, Jin e Swinney (2009) demonstraram que a dimensão cumprimento/confiabilidade foi denotada como o mais forte antecedente da satisfação online e da confiança online; o design do site aumentou o nível da satisfação online dos consumidores; o fator 
DETERMINANTES DA LEALDADE ONLINE EM

SITES DE ALOJAMENTO: UM ESTUDO

COMPARATIVO DO COMPORTAMENTO DO

CONSUMIDOR PORTUGUÊS E BRASILEIRO
Pâmela Mossmann de Aguiar Cristela Maia Bairrada Arnaldo Fernandes Matos Coelho

segurança/privacidade é um indicador da confiança online que, por sua vez, suscita a satisfação online; e, contrariamente ao esperado, a dimensão agilidade de resposta não apresentou qualquer influência sobre a satisfação online e a confiança online.

No setor do turismo, alguns estudos já identificaram alguns elementos da qualidade online que influenciam o valor hedônico e a confiança online do consumidor (que tem como um de seus antecedentes o risco online percebido) (ALBAYRAK et al., 2019; ALI, 2016).

Posto isto, espera-se que a variável qualidade do serviço online influencie positivamente a formação da lealdade online, da confiança online e da satisfação online. Por conseguinte, as seguintes hipóteses são propostas:

H11: A qualidade online está positivamente relacionada com o valor hedônico.

H12: A qualidade online está positivamente relacionada com o valor percebido pelo consumidor.

H13: A qualidade online está positivamente relacionada com o valor utilitário.

H14: A qualidade online está negativamente relacionada com o risco online percebido.

\subsubsection{Personalização}

A personalização é a habilidade de oferecer produtos sob medida e experiências de compra de forma proativa conforme o gosto individual dos consumidores, baseado nas suas informações pessoais e preferências (CHELLAPA; SIN, 2005; MOBASHER; COOLEY; SRIVASTAVA, 2000). Para que isso ocorra, terão de ser considerados dois fatores: (1) A capacidade dos vendedores de adquirirem e processarem informações dos consumidores, e (2) A disposição dos consumidores em partilhar informações e em utilizar os serviços personalizados, visto que muitos consumidores se preocupam com a sua privacidade (CHELLAPA; SIN, 2005; LEE; CRANAGE, 2011).

A personalização traz vantagens tanto para os consumidores quanto para os varejistas online. Eficiência, conveniência, individualização, acolhimento, melhor qualidade do serviço prestado, melhor experiência de compra são alguns dos benefícios recebidos pelos consumidores com a personalização (KIM; LEE, 2009; LEE; CRANAGE, 2011). Já para os varejistas online, podemos citar a redução do risco percebido e a criação de uma confiança emocional dos consumidores em relação a eles (LEE; PARK, 2009).

Lee e Cranage (2011) constataram que os clientes de sites de viagens não se incomodam com a presença de serviços personalizados. Isso pode ocorrer pelo fato de os sites de viagens online serem menos invasivos em relação à privacidade. Os resultados de Piccoli, Lui e Grün (2017) indicaram que o 
DETERMINANTES DA LEALDADE ONLINE EM

SITES DE ALOJAMENTO: UM ESTUDO

COMPARATIVO DO COMPORTAMENTO DO

CONSUMIDOR PORTUGUÊS E BRASILEIRO
Pâmela Mossmann de Aguiar Cristela Maia Bairrada Arnaldo Fernandes Matos Coelho

engajamento na personalização do serviço baseado na Tecnologia da Informação (TI) aumenta a taxa de valor percebido pelos consumidores.

Baseado no conteúdo exposto acima, propõe-se a seguinte hipótese de estudo em relação à personalização de um site:

H15: A personalização de um site influencia positivamente o valor percebido pelo consumidor.

\subsubsection{Aprendizagem}

A aprendizagem, no contexto dos sites pode ser explicada como a sua capacidade em ajudar os consumidores a tornarem-se mais entendidos sobre os produtos, tomarem boas decisões, tornarem-se mais inteligentes e atualizados sobre as coisas que lhes interessam, e estimulá-los a pensar sobre as coisas de novas maneiras (ALNAWAS; ABURUB, 2016).

Jeppesen e Molin (2003) verificaram que uma das forças de uma comunidade online é a sua capacidade de comunicação interativa em escala global. Nela a aprendizagem é, muitas vezes, aprimorada porque as pessoas podem confrontar diferentes tipos de ideias, coletar diferentes tipos de dados, usar diferentes ferramentas e experimentar diferentes pressões em relação ao problema dado.

Alnawas e Aburub (2016) afirmam que a interação dos consumidores com os sites e as aplicações das marcas são uma fonte essencial de valor e que pode influenciar a sua futura satisfação e as suas intenções de compra. Ademais, os benefícios utilitários e hedônicos são importantes na adoção e no uso de recursos, serviços e marketing online.

Desse modo, propõe-se a seguinte hipótese em relação à variável aprendizagem:

H16: A aprendizagem está positivamente relacionada com o valor utilitário.

\subsubsection{Boca-a-boca online recebido}

O boca-a-boca eletrônico pode ser definido como qualquer declaração positiva ou negativa realizada por consumidores potenciais, reais ou anteriores sobre um produto ou empresa, disponível para uma grande quantidade de pessoas e de instituições via Internet, de forma rápida, gratuita e de uma fonte independente (YOO; SANDERS; MOON, 2013). Ele é praticado em blogs, motores de busca, comunidades da Internet, mídias sociais, etc. (YOO; SANDERS; MOON, 2013).

Hussain et al. (2018) constataram que o boca-a-boca online tem um impacto positivo sobre a qualidade do argumento e o risco percebido quando leem informações antes de consumir.

Sendo assim, propõe-se a seguinte hipótese em relação à variável boca-a-boca recebido online: 
DETERMINANTES DA LEALDADE ONLINE EM

SITES DE ALOJAMENTO: UM ESTUDO

COMPARATIVO DO COMPORTAMENTO DO

CONSUMIDOR PORTUGUÊS E BRASILEIRO
Pâmela Mossmann de Aguiar Cristela Maia Bairrada Arnaldo Fernandes Matos Coelho

H17: O boca-a-boca online recebido está positivamente relacionado com o risco online percebido pelo consumidor.

\section{Metodologia}

\subsection{Modelo conceitual}

Este estudo foi realizado com consumidores brasileiros e portugueses e a Modelagem de Equações Estruturais (MEE) foi o método escolhido para testar as hipóteses de estudo propostas. A figura 1 apresenta o modelo conceitual concebido para esta pesquisa. O modelo de investigação proposto dispõe de treze construtos, sendo a lealdade online do consumidor a variável que se pretende explicar a partir da influência dos outros doze construtos.

Figura 1. Modelo conceitual

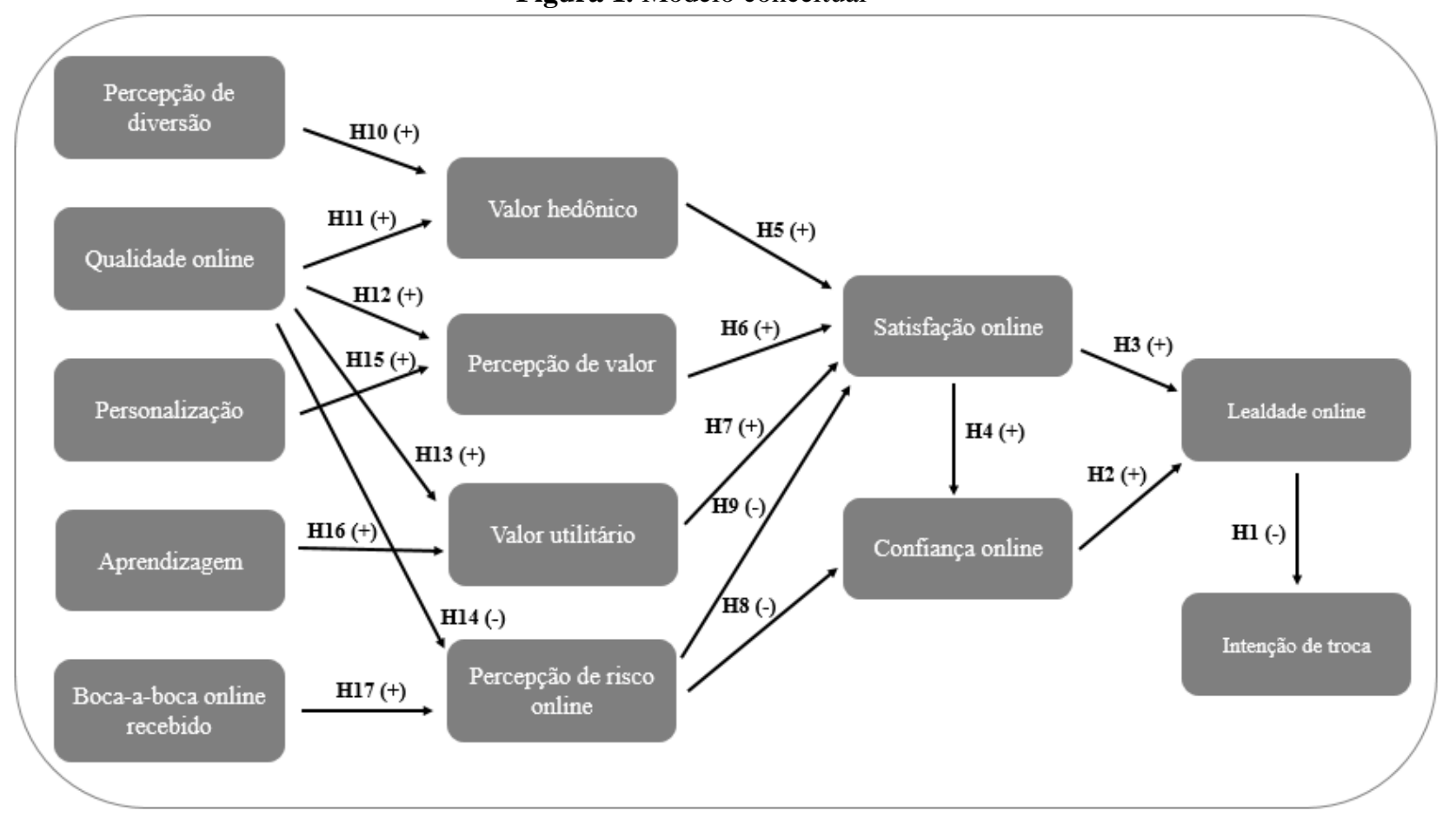

Fonte: Elaborado pelos autores.

\subsection{A amostra}

Para este estudo, delimitou-se como população todos os consumidores brasileiros e portugueses que já efetivaram, ao menos uma vez, a reserva de um alojamento por meio da Web. A amostra foi selecionada por meio do método de amostragem não-probabilística por redes (também conhecida como

Observatório de Inovação do Turismo - Revista Acadêmica 
amostragem bola de neve). As respostas foram recolhidas entre os meses de janeiro e abril de 2018, tendo o inquérito sido divulgado pelo Facebook e por meio do envio de e-mails. A partir de um grupo inicial de 20 pessoas, pediu-se a cada respondente que identificasse mais 3 a 5 novos respondentes até chegar à amostra final de 227 brasileiros e 255 portugueses. Na tabela 1 encontra-se detalhado o perfil dos respondentes brasileiros e portugueses:

Tabela 1. Perfil dos respondentes

\begin{tabular}{|c|c|c|c|c|c|c|c|c|c|c|}
\hline Gênero & Brasileiros & $\%$ & Portugueses & $\%$ & Idade & Brasileiros & & Portugueses & & \\
\hline Feminino & 170 & $74,9 \%$ & 228 & $89,4 \%$ & Minima & 17 & & 17 & & \\
\hline Masculino & 57 & $25,1 \%$ & 27 & $10,6 \%$ & Máxima & 69 & & 79 & & \\
\hline Total & 227 & $100 \%$ & 255 & $100 \%$ & Média & 38 & & 32 & & \\
\hline Família & Brasileiros & $\%$ & Portugueses & $\%$ & Nível de escolaridade & Brasileiros & $\%$ & Portugueses & $\%$ & \\
\hline 1 pessoa & 81 & $35,7 \%$ & 44 & $17,3 \%$ & Ensino Médio & 10 & $4,4 \%$ & 30 & $11,8 \%$ & \\
\hline 2 pessoas & 61 & $26,9 \%$ & 76 & $29,8 \%$ & Ensino Técnico & 10 & $4,4 \%$ & 9 & $3,5 \%$ & \\
\hline 3 pessoas & 45 & $19,8 \%$ & 57 & $22,4 \%$ & Graduação & 90 & $39,6 \%$ & 143 & $56,1 \%$ & \\
\hline 4 pessoas & 29 & $12,8 \%$ & 60 & $23,5 \%$ & Pós-Graduação & 68 & $30,0 \%$ & 3 & $1,2 \%$ & \\
\hline 5 pessoas & 7 & $3,1 \%$ & 13 & $5,1 \%$ & Mestrado & 40 & $17,6 \%$ & 56 & $22,0 \%$ & \\
\hline 6 pessoas ou mais & 4 & $1,8 \%$ & 3 & $1,2 \%$ & Doutorado & 8 & $3,5 \%$ & 14 & $5,5 \%$ & \\
\hline Não respondeu & 0 & $0,0 \%$ & 2 & $0,8 \%$ & Pós-Doutorado & 1 & $0,4 \%$ & 0 & $0,0 \%$ & \\
\hline Total & 227 & $100 \%$ & 255 & $100 \%$ & Total & 227 & $100 \%$ & 255 & $100 \%$ & \\
\hline Profissão & Brasileiros & $\%$ & Portugueses & $\%$ & Renda líquida mensal & Brasileiros & $\%$ & & Portugueses & $\%$ \\
\hline Trabalhador assalariado & 86 & $37,9 \%$ & 133 & $52,2 \%$ & Menos de RS 954 & 0 & $0 \%$ & Menos de $500 €$ & 8 & $3,1 \%$ \\
\hline Trabalhador autônomo & 47 & $20,7 \%$ & 70 & $27,5 \%$ & RS 954-RS 2,999 & 24 & $10,6 \%$ & $500 €-999 €$ & 52 & $20,4 \%$ \\
\hline Trabalhador(a) e estudante & 33 & $14,5 \%$ & 13 & $5,1 \%$ & RS 3,000 -RS 4,999 & 73 & $32,2 \%$ & $1,000 €-1,499 €$ & 51 & $20,0 \%$ \\
\hline Estudante & 28 & $12,3 \%$ & 14 & $5,5 \%$ & RS 5,000 -RS 6,999 & 37 & $16,3 \%$ & $1,500 €-2,499 €$ & 82 & $32,2 \%$ \\
\hline Desempregado(a) & 8 & $3,5 \%$ & 19 & $7,5 \%$ & RS 7,000-RS 8,999 & 31 & $13,7 \%$ & $2,500 €-4,999 €$ & 43 & $16,9 \%$ \\
\hline Assalariado e autônomo & 1 & $0,4 \%$ & 0 & $0,0 \%$ & RS 9,000 ou mais & 62 & $27,3 \%$ & $5,000 €$ ou mais & 19 & $7,5 \%$ \\
\hline Aposentado(a) & 18 & $7,9 \%$ & 5 & $2,0 \%$ & Total & 227 & $100 \%$ & & 255 & $100 \%$ \\
\hline Do lar & 6 & $2,6 \%$ & 1 & $0,4 \%$ & & & & & & \\
\hline Total & 227 & $100 \%$ & 255 & $100 \%$ & & & & & & \\
\hline
\end{tabular}

Fonte: Elaborada pelos autores.

\subsection{O questionário}

Neste estudo, as perguntas do questionário caracterizaram-se por serem de múltipla escolha, avaliadas por uma escala de Likert de 7 pontos, onde os respondentes indicam um grau de concordância ou discordância em relação aos diferentes itens que constituem cada uma das escalas (MALHOTRA, 1999). O questionário foi desenvolvido a partir de métricas selecionadas, traduzidas e adaptadas dos trabalhos originais de diferentes autores da literatura consultada para medir as variáveis latentes que constituem o modelo conceitual deste trabalho (Apêndice I): percepção de diversão (FANG; SHAO; WEN, 2016), qualidade online (KIM; JIN; SWINNEY, 2009), personalização (KIM et al., 2011), aprendizagem (ALNAWAS; ABURUB, 2016), bocaaboca online recebido (LIANG, 2017), valor hedônico (MOUAKKET; AL-HAWARI, 2012), percepção de valor (LI et al., 2015), valor utilitário (MOUAKKET; AL-HAWARI, 2012), percepção de risco (ALCÁNTARA-PILAR et al., 2015), satisfação online (GRACIA; ARIÑO; BLASCO, 2015), confiança online (FORGAS et al., 2012), 
lealdade online (AUDRAIN-PONTEVIA; N'GOALA; PONCIN, 2013), e intenção de troca (FUENTES-BLASCO et al., 2010).

Importa ainda destacar que, no âmbito deste estudo, foi realizado um pré-teste, tendo sido solicitado a 5 académicos e a 15 respondentes comuns para responderem e avaliarem a clareza e lógica das questões.

\subsection{Análise fatorial confirmatória (AFC)}

A análise das respostas baseou-se na Modelagem de Equações Estruturais (MEE), efetuada no software estatístico IBM AMOS, versão 25. A amostra global foi posteriormente dividida em dois grupos (Brasileiros e Portugueses), com o intuito de entendermos a influência cultural na construção da lealdade online.

Após a análise dos índices de modificação, obteve-se a versão final do modelo de mensuração, que apresentou um bom fit: $\chi 2=2093,8 ; \mathrm{df}=821 ; \chi 2 / \mathrm{df}=2,550 ;$ Incremental Fit Index (IFI) = 0,933; Tucker Lewis Index $(\mathrm{TLI})=0,923$; Comparative Fit Index $(\mathrm{CFI})=0,933$; Root Mean Square Error of Approximation $(\mathrm{RMSEA})=0,057$. Os índices IFI, TLI e CFI acima de 0,9, e o RMSEA igual a 0,057, configuram um bom ajustamento do modelo, segundo (MARÔCO, 2010).

A tabela 2 exibe a avaliação das variáveis latentes que compõem o modelo conceitual deste estudo. A validade discriminante dos construtos que compõem o modelo de medida elaborado para esta pesquisa foi testada seguindo as sugestões de Fornell e Larcker (1981), em que todos os construtos são significativamente menores que 1 e as correlações ao quadrado calculadas para cada par de construtos é sempre menor que a variância extraída para os construtos correspondentes (tabela 2).

Tabela 2. Avaliação das variáveis latentes

\begin{tabular}{|c|c|c|c|c|c|c|c|c|c|c|c|c|c|c|c|c|}
\hline Variável & DP & $\mathrm{X} 1$ & $\mathrm{x} 2$ & $\mathrm{X3}$ & $\mathrm{x} 4$ & $\mathrm{x} 5$ & $\mathrm{X6}$ & $\mathrm{X7}$ & $\mathrm{X8}$ & $\mathrm{X9}$ & $\mathrm{X} 10$ & $\mathrm{X} 11$ & $\mathrm{X} 12$ & $\mathrm{X} 13$ & CR & $\overline{\mathrm{AVE}}$ \\
\hline Percepção de diversão (X1) & 1,167 & 0,871 & & & & & & & & & & & & & 0,875 & 0,699 \\
\hline Personalização (X2) & 1,082 & 0,717 & 0,775 & & & & & & & & & & & & 0,777 & 0,538 \\
\hline Aprendizagem (X3) & 1,077 & 0,527 & 0,586 & 0,853 & & & & & & & & & & & 0,860 & 0,674 \\
\hline Boca-a-boca online recebido (X4) & 0,938 & 0,369 & 0,391 & 0,581 & 0,821 & & & & & & & & & & 0,864 & 0,687 \\
\hline Qualidade online (X5) & 0,961 & 0,650 & 0,716 & 0,587 & 0,550 & 0,897 & & & & & & & & & 0,896 & 0,683 \\
\hline Valor hedônico (X6) & 1,492 & 0,653 & 0,522 & 0,546 & 0,492 & 0,489 & 0,929 & & & & & & & & 0,930 & 0,815 \\
\hline Percepção de valor (X7) & 1,132 & 0,487 & 0,454 & 0,493 & 0,474 & 0,588 & 0,478 & 0,947 & & & & & & & 0,948 & 0,858 \\
\hline Valor utilitário (X8) & 0,908 & 0,442 & 0,372 & 0,391 & 0,569 & 0,620 & 0,399 & 0,619 & 0,937 & & & & & & 0,938 & 0,835 \\
\hline Confiança online (X9) & 0,978 & 0,544 & 0,604 & 0,549 & 0,560 & 0,827 & 0,465 & 0,602 & 0,632 & 0,868 & & & & & 0,872 & 0,695 \\
\hline Percepção de risco online (X10) & 1,366 & 0,405 & 0,500 & 0,425 & 0,419 & 0,622 & 0,427 & 0,605 & 0,568 & 0,662 & 0,909 & & & & 0,915 & 0,783 \\
\hline Satisfação online (X11) & 0,981 & 0,546 & 0,627 & 0,562 & 0,565 & 0,816 & 0,505 & 0,698 & 0,632 & 0,969 & 0,724 & 0,889 & & & 0,900 & 0,751 \\
\hline Intenção de troca (X12) & 1,566 & 0,363 & 0,486 & 0,397 & 0,158 & 0,390 & 0,333 & 0,315 & 0,122 & 0,421 & 0,305 & 0,449 & 0,938 & & 0,939 & 0,838 \\
\hline Lealdade online (X13) & 1,018 & 0,479 & 0,508 & 0,473 & 0,588 & 0,721 & 0,368 & 0,590 & 0,639 & 0,871 & 0,604 & 0,874 & 0,375 & 0,800 & 0,875 & 0,710 \\
\hline
\end{tabular}

Fonte: Elaborada pelos autores.

Observatório de Inovação do Turismo - Revista Acadêmica

Vol. XIV, $\mathrm{n}^{\circ} 3$, dezembro - 2020 


\section{Resultados e discussão}

O modelo estrutural final também apresentou um bom fit: $\chi^{2}=3839,105 ; \mathrm{df}=1744 ; \chi^{2} / \mathrm{df}=$ 2,201; Incremental Fit Index (IFI) = 0,893; Tucker Lewis Index (TLI) $=0,883 ;$ Comparative Fit Index $(\mathrm{CFI})=0,892$; Root Mean Square Error of Approximation $(\mathrm{RMSEA})=0,05$. Os índices IFI, TLI e CFI muito próximos de 0,9, e o RMSEA igual a 0,05 , configuram um bom ajustamento do modelo, de acordo com (MARÔCO, 2010).

Para atestar a fiabilidade individual dos construtos manifestos (itens que medem cada construto latente do modelo), foi utilizado o Stardardized Regression Weight (SRW), cujos valores superiores ou iguais a 0,25 indicam a fiabilidade individual apropriada (MARÔCO, 2010). Destaca-se ainda o fato de $\mathrm{R}^{2}$ da lealdade online ser para a amostra global de 0,776 , para a amostra portuguesa de 0,787 e para a amostra brasileira de 0,770 , o que denota uma boa capacidade do modelo. Finalmente, é importante referir que se utilizou a análise multigrupos para comparar os resultados para brasileiros e portugueses, conforme a tabela 3 .

Tabela 3. Resultados do teste de hipóteses

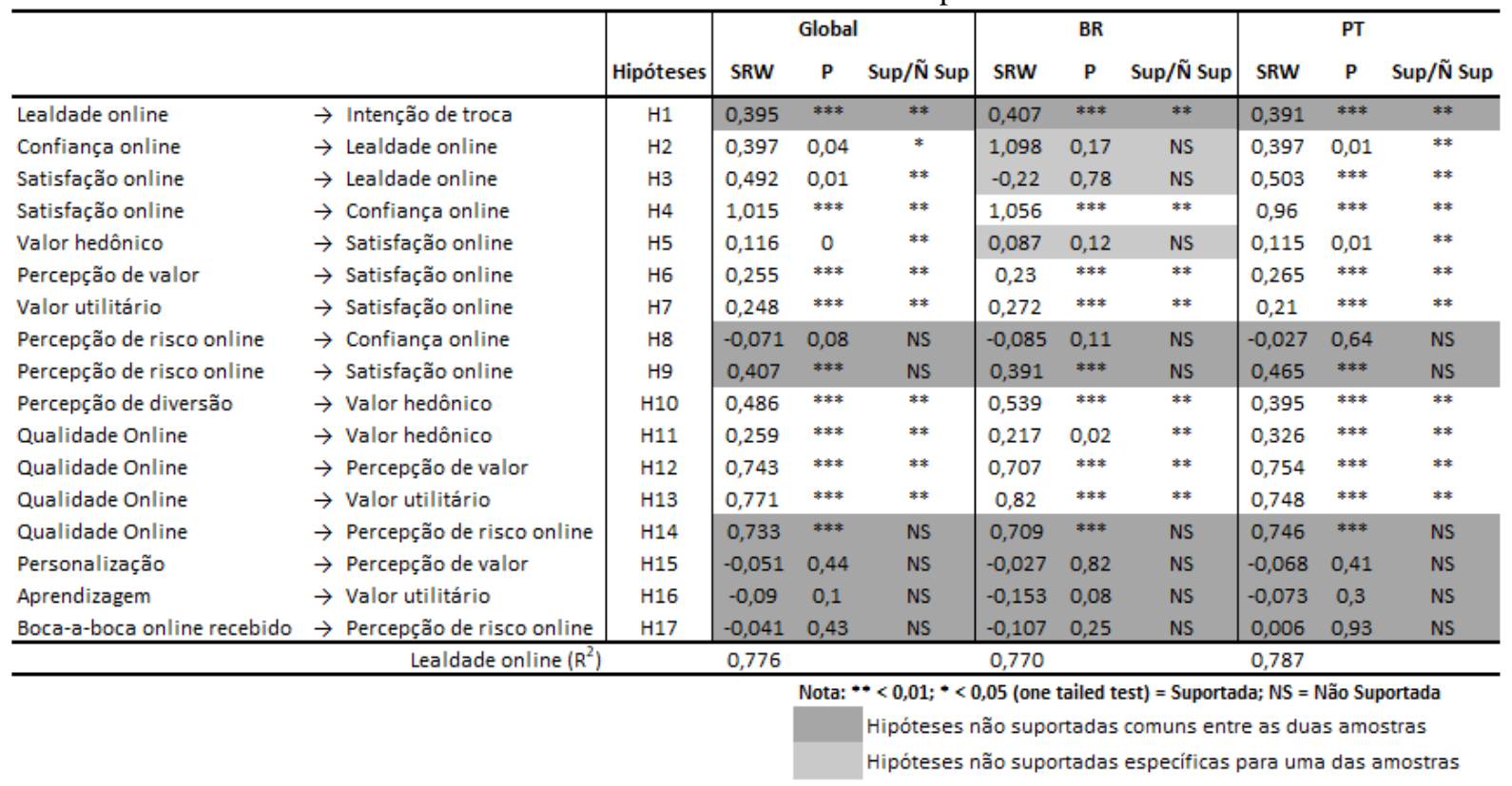

Fonte: Elaborado pelos autores.

Das 17 hipóteses de investigação propostas, 7 não foram suportadas em nenhum dos três contextos considerados (H1, H8, H9, H14, H15, H16 e H17). Já H2, H3 e H5 não foram suportadas somente para a amostra de brasileiros.

O impacto da confiança online sobre a lealdade online $(\mathrm{H} 2)$ não se mostrou relevante para a amostra de brasileiros $(\mathrm{P}>0,10)$, contrariando o resultado obtido para os portugueses $(\mathrm{P}<0,05)$ e a

Observatório de Inovação do Turismo - Revista Acadêmica

Vol. XIV, $\mathrm{n}^{\circ} 3$, dezembro - 2020 
DETERMINANTES DA LEALDADE ONLINE EM

SITES DE ALOJAMENTO: UM ESTUDO

COMPARATIVO DO COMPORTAMENTO DO

CONSUMIDOR PORTUGUÊS E BRASILEIRO
Pâmela Mossmann de Aguiar Cristela Maia Bairrada Arnaldo Fernandes Matos Coelho

própria literatura, já que pesquisas anteriores demonstraram justamente o contrário (FLAVIÁN; GUINALÍU; GURREA, 2006; PONTE; TRUJILLO; RODRÍGUEZ, 2015; REICHHELD; SCHEFTER, 2000).

A relação entre a satisfação online e a lealdade online (H3) também não foi suportada para os brasileiros $(\mathrm{P}>0,10)$, ao contrário dos portugueses $(\mathrm{P}<0,01)$ e de estudos preliminares, que concluíram que a satisfação online influencia positivamente a lealdade online (ANDERSON; SWAMINATHAN, 2011; CHANG; CHEN, 2009). A correspondência positiva entre a satisfação online e a confiança online (H4) foi suportada para as duas amostras ( $<<0,01)$, o que corrobora o estudo de Anderson e Swaminathan (2011).

No que tange ao impacto positivo do valor hedônico sobre a satisfação online (H5), mais uma vez os brasileiros divergiram do cenário esperado, uma vez que a hipótese não foi suportada para esta amostra $(\mathrm{P}>0,10)$, enquanto para os portugueses $\mathrm{H} 5$ foi sustentada $(\mathrm{P}<0,05)$. O resultado dos portugueses confirma as conclusões de estudos prévios, os quais apontam que o valor hedônico contribui de maneira positiva com a satisfação online (ATULKAR; KESARI, 2017; KESARI; ATULKAR, 2016; SCARPI; PIZZI; VISENTIN, 2014), embora ainda não haja um consenso na literatura a este respeito.

A hipótese que propõe a relação positiva entre o valor utilitário e a satisfação online $(\mathrm{H} 7)$ foi suportada para as duas amostras (ambas com valores de $\mathrm{P}<0,01$ ). Essa influência já foi detectada nos trabalhos de autores que estudam o valor hedônico e o valor utilitário (JONES; REYNOLDS; ARNOLD, 2006; KESARI; ATULKAR, 2016; SCARPI; PIZZI; VISENTIN, 2014).

No que concerne à influência positiva do valor percebido sobre a satisfação online, H6 foi sustentada para as duas amostras $(\mathrm{P}<0,01)$. $\mathrm{O}$ resultado vai ao encontro das conclusões de Yang e Peterson (2004).

No tocante às duas hipóteses levantadas para a atuação negativa do construto risco online percebido sobre a confiança online e a satisfação online (H8 e H9, respectivamente), nenhuma das duas hipóteses foram ratificadas para nenhuma das duas amostras. A não confirmação de H8 é suportada pelo estudo de Miyazaki e Fernandez (2001). Outra explicação pode ser o fato de atualmente existirem muito mais mecanismos de proteção online, como é o caso dos selos de certificação dos sites, o General Data Protection Regulation (GDPR) ou Regulamento Geral de Proteção de Dados), os avisos de cookies nos sites no momento da navegação, entre outros. Relativamente à influência negativa da percepção de risco sobre a satisfação online (H9), faltam estudos que avaliem a influência direta do risco online percebido sobre a satisfação online.

Conforme esperado, H10 (efeito positivo da percepção de diversão sobre o valor hedônico) foi ratificada para as duas amostras. Esta conclusão está em conformidade com estudos anteriores (SARKAR, 2011; TASCI; KO, 2015). O impacto da qualidade online sobre o desempenho dos 
DETERMINANTES DA LEALDADE ONLINE EM

SITES DE ALOJAMENTO: UM ESTUDO

COMPARATIVO DO COMPORTAMENTO DO

CONSUMIDOR PORTUGUÊS E BRASILEIRO
Pâmela Mossmann de Aguiar Cristela Maia Bairrada Arnaldo Fernandes Matos Coelho

construtos valor hedônico, valor percebido e valor utilitário foi confirmado (H11, H12 e H13, respectivamente). Já a hipótese que testou a relação negativa entre a qualidade online e a percepção de risco (H14) não se confirmou. Pesquisas anteriores já haviam demonstrado a participação da qualidade online na formação da satisfação, da confiança e da lealdade online, assim como a sua influência sobre o valor hedônico (BAUER; FALK; HAMMERSCHMIDT, 2006; KIM; JIN; SWINNEY, 2009). No que tange à rejeição de H14, ainda não existe um consenso na literatura sobre a relação negativa entre a qualidade online e a percepção de risco.

O efeito da personalização sobre o valor percebido (H15) foi refutado para as duas amostras (P $>0,10$ ), além de ter apresentado uma relação negativa (quando o proposto neste trabalho era uma relação positiva). Este comportamento vai ao encontro do que Lee e Cranage (2011) relataram no seu trabalho, mas ainda existem muitas divergências acerca do tema na literatura.

A interação entre a aprendizagem e o valor utilitário (H16) não foi suportada para ambas as amostras ( $\mathrm{P}>$ 0,10 para os portugueses, e relação negativa para os brasileiros). Esses resultados contrariam as conclusões de Alnawas e Aburub (2016). A relação entre o boca-a-boca online recebido e o risco online percebido (H17) não foi suportada para nenhuma das duas amostras $(\mathrm{P}>0,10)$, apesar do estudo realizado por Chatterjee (2001) ter indicado o contrário.

A relação entre a lealdade online e a intenção de troca (H1) foi rejeitada para ambas as amostras, pois a relação proposta era negativa, mas os resultados apontaram uma relação positiva. De fato, Antón, Camarero e Carrero (2007) verificaram que não são todos os fatores propostos por eles que influenciam na dissolução da relação entre consumidor e empresa, o que pode explicar H1 não ser suportada para os brasileiros e portugueses.

\section{Considerações finais}

O teste de hipóteses permitiu concluir, quando se atenta para a variável principal, que a relação entre a lealdade online e a intenção de troca (H1) não é significativa, tanto para a amostra de brasileiros quanto para a amostra de portugueses. É necessário fazer um estudo mais minucioso sobre esta relação, de modo a verificar a influência dos diversos fatores que precipitam e predispõem a dissolução da relação consumidor-empresa. Referente às relações entre a lealdade online com os construtos confiança online e satisfação online, as mesmas foram apenas suportadas para a amostra de portugueses. Uma explicação possível para a rejeição de $\mathrm{H} 2$ e $\mathrm{H} 3$ para os brasileiros é a sua maior aderência às compras online (65\%) (ISTOÉ, 2018), quase o dobro quando comparado aos portugueses (36\%) (ITINSIGHT, 2018), bem como a estrutura etária mais velha de Portugal (PORDATA, 2017). Ademais, a confirmação de $\mathrm{H} 2$ e de $\mathrm{H} 3$ para os portugueses pode indicar que estes consumidores evitam arriscar muito, tendo

Observatório de Inovação do Turismo - Revista Acadêmica

Vol. XIV, $\mathrm{n}^{\circ} 3$, dezembro - 2020 
DETERMINANTES DA LEALDADE ONLINE EM

SITES DE ALOJAMENTO: UM ESTUDO

COMPARATIVO DO COMPORTAMENTO DO

CONSUMIDOR PORTUGUÊS E BRASILEIRO
Pâmela Mossmann de Aguiar Cristela Maia Bairrada Arnaldo Fernandes Matos Coelho

maior tendência ao evitamento da incerteza, o que revela serem mais conservadores em relação a mudanças nos seus hábitos (HARYANTO; MOUTINHO; COELHO, 2016). A inclusão de aspectos negativos relativamente ao comportamento de compra pelos portugueses, inclusive associada a aspectos ambientais, geralmente neutros, também podem explicar a maior necessidade dos consumidores portugueses em confiar e estarem satisfeitos com um fornecedor (LINS; POESCHL, 2016).

Das quatro hipóteses sugeridas para as relações com a satisfação online (H5, H6, H7 e H9), duas delas foram suportadas para as duas amostras. A influência do valor hedônico sobre a satisfação online (H5) foi desconsiderada para a amostra de brasileiros, e o impacto da percepção de risco sobre a satisfação online (H9) não foi verificado para as duas amostras. Realmente, os estudos ainda incipientes direcionados ao valor hedônico vinculado à lealdade online e seus precedentes não nos possibilitam afirmar veementemente esta relação. $\mathrm{O}$ mesmo se pode afirmar sobre o impacto da percepção de risco sobre a satisfação online.

Quando se verifica as duas hipóteses propostas para a confiança online (H4 e H8), apenas a associação entre a satisfação online e a confiança online (H4) é aceita. Chang e Chen (2009) já haviam constatado que a falta de segurança é um dos principais fatores que os consumidores consideram ao efetuarem compras num site. Uma justificativa para H8 pode ter a ver com a preocupação cada vez maior com a proteção dos dados pessoais, a qual tem conduzido ao desenvolvimento de ferramentas que ajudam na preservação dessas informações, o que faz que o consumidor se sinta mais seguro ao comprar online.

Das demais oito hipóteses, cinco delas foram rejeitadas para ambas as amostras (H9, H14, H15, H16 e H17). A influência negativa da percepção de risco online sobre a satisfação online (H9) não foi confirmada. A relação entre a qualidade online e a percepção de risco (H14) carece de mais análises, visto que os resultados já apurados apontam para sentidos opostos. Ou seja, alguns pesquisadores encontraram uma relação positiva entre esses construtos, ao passo que outros constataram que existe uma relação negativa entre os mesmos. A não significância do impacto da personalização sobre o valor percebido pelo consumidor (H15) confere com as inferências de Lee e Cranage (2011), já que os consumidores não gostam da ideia de compartilhar as suas informações pessoais com as organizações sem saber para que e como utilizarão esses dados. A rejeição da relação entre a aprendizagem e o valor utilitário (H16) pode ser explicada pela necessidade de empreender mais estudos relativos à atuação da aprendizagem sobre os fatores que levam à lealdade online. A recusa da relação entre o boca-a-boca online recebido e o risco online percebido (H17) encontra fundamento nas conclusões de Chatterjee (2001) de que consumidores que compram de fornecedores que conhecem estão menos propensos a mudar a sua intenção de compra quando submetidos ao boca-a-boca negativo, quando comparados a consumidores que compram de fornecedores pelo preço.

Observatório de Inovação do Turismo - Revista Acadêmica

Vol. XIV, $\mathrm{n}^{\circ} 3$, dezembro - 2020 
DETERMINANTES DA LEALDADE ONLINE EM

SITES DE ALOJAMENTO: UM ESTUDO

COMPARATIVO DO COMPORTAMENTO DO

CONSUMIDOR PORTUGUÊS E BRASILEIRO
Pâmela Mossmann de Aguiar Cristela Maia Bairrada Arnaldo Fernandes Matos Coelho

Baseado no exposto acima, é possível observar o comportamento distinto entre brasileiros e portugueses em alguns aspectos relacionados à lealdade online, além de verificar que os construtos propostos no modelo de pesquisa podem contribuir e influenciar a lealdade online a sites de reserva de alojamento.

\subsection{Contribuições teóricas}

Este trabalho apresenta cinco contribuições que devem ser destacadas: 1) Apresenta um modelo completo que identifica a constelação de determinantes da lealdade online; 2) Considera variáveis de natureza cognitiva (como o valor utilitário, o valor percebido, o boca-a-boca online recebido), quanto afetiva (como o valor hedônico, a perceção de diversão, a aprendizagem); 3) Introduz a variável intenção de troca que é uma das consequências negativas mais relevantes da lealdade ou, se se quiser, da ausência dela; 4) Apresenta uma cadeia de efeitos complexa que permite uma melhor compreensão do processo da lealdade; e finalmente 5) Este estudo baseia-se em duas amostras, uma de respondentes brasileiros e outra portugueses, que permite integrar as diferenças culturais na análise.

Mesmo que os resultados não possam ser estendidos para toda a população de brasileiros e portugueses, podemos depreender que há indícios de que as diferenças culturais influenciam na propensão dos cidadãos de diferentes países serem ou não leais a empresas online.

\subsection{Contribuições para a gestão}

No que diz respeito ao contexto prático da gestão, este estudo possibilita extrair contribuições relativas as quais elementos as empresas devem focar-se para angariar clientes leais. Ações voltadas para o aumento da satisfação online - vinculadas à percepção de diversão ao comprar, valor hedônico, valor utilitário, valor percebido e qualidade online - e da confiança online (associadas à qualidade online, especialmente no que toca à segurança e privacidade do site, e à percepção de risco) merecem especial destaque. As comunidades virtuais que incentivem a interação entre os consumidores também requerem atenção, uma vez que pesquisas anteriores demonstraram que esse tipo de movimento desperta maior interesse dos consumidores em aprender mais sobre a empresa e os seus produtos e serviços (BICKART; SCHINDLER，2001; ANDERSON; SWAMINATHAN， 2011； SRINIVASAN; ANDERSON; PONNAVOLU, 2002), além de favorecerem o desenvolvimento do boca-a-boca e propiciarem um ambiente divertido e descontraído aos consumidores. Por fim, é importante mencionar o cuidado que as empresas devem ter em relação às diferenças culturais dos mercados onde atuam, de maneira a terem um site mais universal.

Observatório de Inovação do Turismo - Revista Acadêmica

Vol. XIV, nº 3, dezembro - 2020 
DETERMINANTES DA LEALDADE ONLINE EM

SITES DE ALOJAMENTO: UM ESTUDO

COMPARATIVO DO COMPORTAMENTO DO

CONSUMIDOR PORTUGUÊS E BRASILEIRO
Pâmela Mossmann de Aguiar Cristela Maia Bairrada Arnaldo Fernandes Matos Coelho

\subsection{Limitações e sugestões para pesquisas futuras}

Esta investigação apresenta algumas limitações, como o fato de os seus resultados não poderem ser generalizados para toda a população brasileira e portuguesa, devido ao método de amostragem escolhido (não-probabilístico e snowball). Além disso, há relações entre os construtos que não foram analisadas e que podem ser relevantes para o estudo da lealdade online.

Para as pesquisas futuras, sugere-se a análise das relações diretas de outros construtos com a lealdade online (como valor percebido, qualidade do serviço online, boca-a-boca recebido, preço), bem como entre qualidade online e satisfação online, e qualidade online e confiança online; e consequentes da lealdade online (como boca-a-boca positivo e relação com a marca). Uma última sugestão corresponde à inclusão da variável intenção de compra como um antecedente da lealdade online (CHANG; CHEN, 2009; CHATTERJEE, 2001; PONTE; TRUJILLO; RODRÍGUEZ, 2015).

\section{Referências}

AGAG, G. M.; EL-MASRY, A. A. Why do consumers trust online travel websites? Drivers and outcomes of consumer trust toward online travel websites. Journal of Travel Research, v. 56, n. 3, p. 347-369, apr. 2016.

ALBAYRAK, T. et al. Customer loyalty towards travel agency websites: the role of trust and hedonic value. Journal of Quality Assurance in Hospitality and Tourism, v. 21, n. 1, p. 50-77, may 2019.

ALCÁNTARA-PILAR, J. M. et al. Motivational duality in online consumer behaviour: website usability and flow state as moderating factors. International Journal of Business and Economics, v. 14, n. 1, p. 79-104, jun. 2015.

ALCÁNTARA-PILAR, J. M. et al. The antecedent role of online satisfaction, perceived risk online, and perceived website usability on the affect towards travel destinations. Journal of Destination Marketing \& Management, v. 9, p. 20-35, sep. 2018.

ALI, F. Hotel website quality, perceived flow, customer satisfaction and purchase intention. Journal of Hospitality and Tourism Technology, v. 7, n. 2, p. 213-228, may 2016.

ALNAWAS, I.; ABURUB, F. The effect of benefits generated from interacting with branded mobile apps on consumer satisfaction and purchase intentions. Journal of Retailing and Consumer Services, v. 31, p. 313-322, jul. 2016.

ANDERSON, R. E.; SRINIVASAN, S. S. E-Satisfaction and E-Loyalty: a contingency framework. Psychology and Marketing, v. 20, n. 2, p. 123-138, jan. 2003. 
ANDERSON, R. E.; SWAMINATHAN, S. Customer satisfaction and loyalty in e-markets: A PLS path modeling approach. The Journal of Marketing Theory and Practice, v. 19, n. 2, p. 221-234, Spring 2011.

ANTÓN, C.; CAMARERO, C.; CARRERO, M. The mediating effect of satisfaction on consumers' switching intention. Psychology \& Marketing, v. 24, n. 6, p. 511-538, jun. 2007.

ATULKAR, S.; KESARI, B. Satisfaction, loyalty and repatronage intentions: role of hedonic shopping values. Journal of Retailing and Consumer Services, v. 39, p. 23-34, nov. 2017.

AUDRAIN-PONTEVIA, A. F.; N'GOALA, G.; PONCIN, I. A good deal online: the impacts of acquisition and transaction value on E-satisfaction and E-loyalty. Journal of Retailing and Consumer Services, v. 20, n. 5, p. 445-452, sep. 2013.

BATRA, R.; AHTOLA, O. T. Measuring the hedonic and utilitarian sources of consumer attitudes. Marketing Letters, v. 2, n. 2, p. 159-170, 1990.

BAUER, H. H.; FALK, T.; HAMMERSCHMIDT, M. eTransQual: a transaction process-based approach for capturing service quality in online shopping. Journal of Business Research, v. 59, n. 7, p. 866-875, jul. 2006.

BICKART, B.; SCHINDLER, R. M. Internet forums as influential sources of consumer information. Journal of Interactive Marketing, v. 15, n. 3, p. 31-40, Summer 2001.

BOLTON, R. N.; LEMON, K. N. A dynamic model of customers' usage of services: usage as an antecedent and consequence of satisfaction. Journal of Marketing Research, v. 36, n. 2, p. 171-186, may 1999.

BÜTTNER, O. B.; FLORACK, A.; GÖRITZ, A. S. Shopping orientation and mindsets: how motivation influences consumer information processing during shopping. Psychology \& Marketing, v. 30, n. 9, p. 779-793, jul. 2013.

CHANG, H. H.; CHEN, S. W. The impact of customer interface quality, satisfaction and switching costs on e-loyalty: Internet experience as a moderator. Computers in Human Behavior, v. 24, n. 6, p. 2927-2944, sep. 2008.

CHANG, H. H.; CHEN, S. W. Consumer perception of interface quality, security, and loyalty in electronic commerce. Information and Management, v. 46, n. 7, p. 411-417, oct. 2009.

CHATTERJEE, P. Online reviews: do consumers use them? NA - Advances in Consumer Research. v. 28, p. 129-133, 2001.

CHELLAPA, R. K.; SIN, R. G. Personalization versus privacy: an empirical examination of the online consumer's dilemma. Information Technology and Management, v. 6, p. 181-2020, 2005.

CHEN, J. V. et al. Investigating international tourists' intention to revisit myanmar based on need gratification, flow experience and perceived risk. Journal of Quality Assurance in Hospitality and Tourism, v. 18, n. 1, p. 25-44, apr. 2016.

CHILDERS, T. L. et al. Hedonic and utilitarian motivations for online retail shopping behavior. Journal of Retailing, v. 77, n. 4, p. 511-535, Winter 2001. 
CHOI, H.; CHOI, H. C. Investigating tourists' fun-eliciting process toward tourism destination sites: an application of cognitive appraisal theory. Journal of Travel Research, v. 58, n. 5, p. 732-744, may 2019.

CURRAS-PEREZ, R. et al. Determinants of customer retention in virtual environments. The role of perceived risk in a tourism services context. Spanish Journal of Marketing - ESIC, v. 21, n. 2, p. 131-145, sep. 2017.

EL-ADLY, M. I. Modelling the relationship between hotel perceived value, customer satisfaction, and customer loyalty. Journal of Retailing and Consumer Services, v. 50, p. 322-332, sep. 2019.

FANG, J.; SHAO, Y.; WEN, C. Transactional quality, relational quality, and consumer e-loyalty: Evidence from SEM and fsQCA. International Journal of Information Management, v. 36, n. 6, Parte B, p. 1205-1217, dec. 2016.

FLAVIÁN, C.; GUINALÍU, M.; GURREA, R. The role played by perceived usability, satisfaction and consumer trust on website loyalty. Information and Management, v. 43, n. 1, p. 1-14, jan. 2006.

FORGAS, S. et al. Online drivers and offline influences related to loyalty to airline websites. Journal of Air Transport Management, v. 18, n. 1, p. 43-46, jan. 2012.

FORNELL, C.; LARCKER, D. F. Evaluating structural equation models with unobservable variables and measurement error. Journal of Marketing Research, v. 18, n. 1, p. 39-50, feb. 1981.

FUENTES-BLASCO, M. et al. Measuring the antecedents of e-loyalty and the effect of switching costs on website. Service Industries Journal, v. 30, n. 11, p. 1837-1852, apr. 2010.

GANESAN, S. Determinants of long-term orientation in buyer-seller relationships. Journal of Marketing, v. 58, n. 2, p. 1-19, apr. 1994.

GHOTBABADI, A. R.; FEIZ, S.; BAHARUN, R. The relationship of customer perceived risk and customer satisfaction. Mediterranean Journal of Social Sciences, v. 7, n. 1, S1, p. 161-173, jan. 2016.

GRACIA, D. B.; ARIÑO, L. V. C.; BLASCO, M. G. The effect of culture in forming e-loyalty intentions: A cross-cultural analysis between Argentina and Spain. Business Research Quarterly, v. 18, n. 4, p. 275-292, oct.-dec. 2015.

GUNDLACH, G. T.; MURPHY, P. E. Ethical and legal foundations of relational marketing exchanges. Journal of Marketing, v. 57, n. 4, p. 35-46, oct. 1993.

HAN, H.; KIM, W.; HYUN, S. S. Switching intention model development: Role of service performances, customer satisfaction, and switching barriers in the hotel industry. International Journal of Hospitality Management, v. 30, n. 3, p. 619-629, sep. 2011.

HARYANTO, J. O.; MOUTINHO, L.; COELHO, A. Is brand loyalty really present in the children's market? A comparative study from Indonesia, Portugal, and Brazil. Journal of Business Research, v, 69, n. 10, p. 4020-4032, oct. 2016. 
HIRSCHMAN, E. C.; HOLBROOK, M. B. Hedonic consumption: emerging concepts, methods and propositions. Journal of Marketing, v. 46, n. 3, p. 92-101, Summer 1982.

HOFSTEDE INSIGHTS. Hofstede Insights, 2020. Disponível em: https://www.hofstedeinsights.com/. Acesso em: 28 Junho 2020.

HSU, M.-H.; CHUANG, L.-W.; HSU, C.-S. Understanding online shopping intention: the roles of four types of trust and their antecedents. Internet Research, v. 24, n. 3, p. 332-352, may 2014.

HUSSAIN, S. et al. Consumers' online information adoption behavior: Motives and antecedents of electronic word of mouth communications. Computers in Human Behavior, v. 80, p. 22-32, mar. 2018.

ISTOÉ. Compra regular na internet é feita por quase 7 a cada 10 brasileiros, diz PwC. Revista IstoÉ, 2018. Disponível em: https://istoe.com.br/compra-regular-na-internet-e-feita-por-quase-7-a-cada-10brasileiros-diz-pwc/. Acesso em: 01 Julho 2018.

ITINSIGHT. ITInsight, 2018. Disponível em: <https://www.itinsight.pt/news/digital/portuguesescompram-cada-vez-mais-online>. Acesso em: 01 Julho 2018.

JARVENPAA, S. L.; TRACTINSKY, N.; VITALE, M. Consumer trust in an Internet store. Information Technology and Management, v. 1, p. 45-71, nov. 2000.

JEPPESEN, L. B.; MOLIN, M. J. Consumers as Co-developers: Learning and Innovation Outside the Firm. Technology Analysis \& Strategic Management, v. 15, n. 3, p. 363-383, 2003.

JONES, M. A.; REYNOLDS, K. E.; ARNOLD, M. J. Hedonic and utilitarian shopping value: investigating differential effects on retail outcomes. Journal of Business Research, v. 59, n. 9, p. 974-981, sep. 2006.

KAMAL, S. B. M. et al. Hotel booking websites and their impact on e-satisfaction and e-loyalty: Analysis on utilitarian and hedonic features. International Journal of Academic Research in Business and Social Sciences, v. 8, n. 15, p. 160-177, dec. 2018.

KESARI, B.; ATULKAR, S. Satisfaction of mall shoppers: A study on perceived utilitarian and hedonic shopping values. Journal of Retailing and Consumer Services, v. 31, p. 22-31, jul. 2016.

KHUONG, M. N. The effects of destination image, perceived value and service quality on tourist return intention through destination satisfaction - A study in ho chi minh city, Vietnam. International Journal of Innovation, Management and Technology, v. 8, n. 5, p. 401-408, oct. 2017.

KIM, E.; LEE, B. E-service quality competition through personalization under consumer privacy concerns. Electronic Commerce Research and Applications, v. 8, n. 4, p. 182-190, jul.-aug. 2009.

KIM, J.; JIN, B.; SWINNEY, J. L. The role of etail quality, e-satisfaction and e-trust in online loyalty development process. Journal of Retailing and Consumer Services, v. 16, n. 4, p. 239-247, jul. 2009.

KIM, K. H.; PARK, D. B. Relationships among perceived value, satisfaction, and loyalty: communitybased ecotourism in Korea. Journal of Travel and Tourism Marketing, v. 34, n. 2, p. 171-191, mar. 2016.

Observatório de Inovação do Turismo - Revista Acadêmica

Vol. XIV, $n^{\circ} 3$, dezembro - 2020 
KIM, M. J.; HALL, C. M. A hedonic motivation model in virtual reality tourism: comparing visitors and non-visitors. International Journal of Information Management, v. 46, p. 236-249, jun. 2019.

KIM, W. G. et al. The influence of hotel website factors on e-loyalty in a B2C context. Tourism Economics, v. 17, n. 5, p. 1103-1127, oct. 2011.

LEE, C. H.; CRANAGE, D. A. Personalisation-privacy paradox: the effects of personalisation and privacy assurance on customer responses to travel Web sites. Tourism Management, v. 32, n. 5, p. 987-994, oct. 2011.

LEE, E.-J.; PARK, J. K. Online service personalization for apparel shopping. Journal of Retailing and Consumer Services, v. 16, n. 2, p. 83-91, mar. 2009.

LEE, S.; KIM, D. Y. The effect of hedonic and utilitarian values on satisfaction and loyalty of Airbnb users. International Journal of Contemporary Hospitality Management, v. 30, n. 3, p. 1332-1351, mar. 2018.

LI, H. et al. The interplay between value and service quality experience: e-loyalty development process through the eTailQ scale and value perception. Electronic Commerce Research, v. 15, n. 4, p. 585-615, sep. 2015.

LIANG, L. J. Understanding repurchase intention of Airbnb consumers: perceived authenticity, electronic word-of-mouth, and price sensitivity. Journal of Travel and Tourism Marketing, v. 35, n. 1, p. 1-58, feb. 2017.

LINS, S. L. B.; POESCHL, G. O que os adolescentes brasileiros e portugueses pensam quando pensam em comprar? Psicologia: Teoria e Pesquisa, v. 32, n. 1, p. 71-79, jan./mar. 2016.

LU, M.-T.; YEUNG, W. A framework for effective commercial Web application development. Internet Research, v. 8, n. 2, p. 166-173, may 1998.

LUO, Y. et al. The impact of interactivity of online tourism websites on customer satisfaction. In: 16th International Conference on Service Systems and Service Management, ICSSSM, Shenzhen, China, 13-15 jul. 2019. p. 1-7.

MALHOTRA, N. K. Marketing research: an applied orientation. $3^{\text {rd }}$. ed. New York: Pearson, 1999. $763 \mathrm{p}$.

MARÔCO, J. Análise de equações estruturais: fundamentos teóricos, software \& aplicações. Portugal: Pêro Pinheiro, 2010. 374 p.

MIYAZAKI, A. D.; FERNANDEZ, A. Consumer perceptions of privacy and security risks for online shopping. The Journal of Consumer Affairs, v. 35, n. 1, p. 27-44, Summer 2001.

MOBASHER, B.; COOLEY, R.; SRIVASTAVA, J. Automatic personalization based on web usage mining. Communications of the ACM, 43, n. 8, p. 142-151, aug. 2000.

MOUAKKET, S.; AL-HAWARI, M. A. Examining the antecedents of e-loyalty intention in an online reservation environment. Journal of High Technology Management Research, v. 23, n. 1, p. 46-57, 2012. 
NIELSEN. Insights Global Connected Commerce. Nielsen. 38 p., jan. 2016.

OLIVER, R. L. Whence Costumer Loyalty? Journal of Marketing, v. 63, p. 33-44, 1999.

OLIVER, R. L. Satisfaction: a behavioral perspective on the consumer. $2^{\text {nd }}$. ed. Boston: Irwin/McGraw-Hill, 2015. 969 p.

OLIVER, R. L.; DESARBO, W. S. Response determinants in satisfaction judgments. The Journal of Consumer Research, v. 14, n. 4, p. 495-507, mar. 1988.

PAPPAS, N. Marketing strategies, perceived risks, and consumer trust in online buying behaviour. Journal of Retailing and Consumer Services, v. 29, p. 92-103, mar. 2016.

PEREIRA, H. G.; SALGUEIRO, M. D. F.; RITA, P. Online purchase determinants of loyalty: the mediating effect of satisfaction in tourism. Journal of Retailing and Consumer Services, v. 30, p. 279-291, may 2016.

PICCOLI, G.; LUI, T. W.; GRÜN, B. The impact of IT-enabled customer service systems on service personalization, customer service perceptions, and hotel performance. Tourism Management, v. 59, p. 349-362, apr. 2017.

PONTE, E. B.; TRUJILLO, E. C.; RODRÍGUEZ, T. E. Influence of trust and perceived value on the intention to purchase travel online: integrating the effects of assurance on trust antecedents. Tourism Management, v. 47, p. 286-302, apr. 2015.

PORDATA. Pordata, 2017. Disponivel em: https://www.pordata.pt/. Acesso em: 01 Jul. 2018. QUELCH, J. A.; KLEIN, L. R. The Internet and International Marketing. Management Review, v. 37, n. 3, p. 60-75, apr. 1996.

REICHHELD, F. F.; SCHEFTER, P. E-Loyalty: your secret weapon on the web. Harvard Business Review, v. 78, n. 4, p. 105-113, jul.-aug. 2000.

SARKAR, A. Impact of utilitarian and hedonic shopping values on individual 's perceived benefits and risks in Online Shopping. International Management Review, v. 7, n. 1, p. 58-95, 2011.

SCARPI, D.; PIZZI, G.; VISENTIN, M. Shopping for fun or shopping to buy: Is it different online and offline? Journal of Retailing and Consumer Services, v. 21, n. 3, p. 258-267, may 2014.

SRINIVASAN, S. S.; ANDERSON, R.; PONNAVOLU, K. Customer loyalty in e-commerce: an exploration of its antecedents and consequences. Journal of Retailing, v. 78, n. 1, p. 41-50, Spring 2002.

TASCI, A. D. A.; KO, Y. J. A fun-scale for understanding the hedonic value of a product: the destination context. Journal of Travel and Tourism Marketing, v. 33, n. 2, p. 162-183, may 2015.

TO, P.-L.; LIAO, C.; LIN, T.-H. Shopping motivations on Internet: a study based on utilitarian and hedonic value. Technovation, v. 27, n. 12, p. 774-787, dec. 2007.

YANG, Z.; PETERSON, R. T. Customer perceived value, satisfaction, and loyalty: the role of switching costs. Psychology and Marketing, v. 21, n. 10, p. 799-822, oct. 2004. 
DETERMINANTES DA LEALDADE ONLINE EM

SITES DE ALOJAMENTO: UM ESTUDO

COMPARATIVO DO COMPORTAMENTO DO

CONSUMIDOR PORTUGUÊS E BRASILEIRO
Pâmela Mossmann de Aguiar Cristela Maia Bairrada Arnaldo Fernandes Matos Coelho

YOO, C. W.; SANDERS, G. L.; MOON, J. Exploring the effect of e-WOM participation on e-Loyalty in e-commerce. Decision Support Systems, v. 55, n. 3, p. 669-678, jun. 2013.

ZHANG, Y.; YANG, Q. Assessing hotel decision-making of disabled guests: satisfaction correlation study between online comments' credibility and perceived risk. Electronic Commerce Research, apr. 2019. 
DETERMINANTES DA LEALDADE ONLINE EM

SITES DE ALOJAMENTO: UM ESTUDO

COMPARATIVO DO COMPORTAMENTO DO

CONSUMIDOR PORTUGUÊS E BRASILEIRO
Pâmela Mossmann de Aguiar Cristela Maia Bairrada Arnaldo Fernandes Matos Coelho

Apêndice I - Apresentação dos construtos e métricas

\begin{tabular}{|c|c|l|}
\hline Variável & \multicolumn{1}{|c|}{ Autor } & \multicolumn{1}{c|}{ Itens } \\
\hline $\begin{array}{c}\text { Perceção de } \\
\text { diversão }\end{array}$ & Fang et al (2016) & 2. Eu achei a minha visita a este site divertida. \\
& 3. Eu achei a minha visita a este site agradável. \\
& 4. Eu achei a minha visita a este site prazerosa. \\
\hline
\end{tabular}

\begin{tabular}{|c|c|c|c|}
\hline Variável & Componentes & Autor & Itens \\
\hline \multirow{4}{*}{$\begin{array}{l}\text { Qualidade } \\
\text { online }\end{array}$} & Desenho do site & \multirow{4}{*}{ Kimet al (2009) } & $\begin{array}{l}\text { 1. Este site é bem desenhado de forma a eu não } \\
\text { perder o meu tempo. } \\
\text { 2. Este site fornece-me informações detalhadas. } \\
\text { 3. Neste site é rápido e fácil completar uma } \\
\text { transação. }\end{array}$ \\
\hline & $\begin{array}{l}\text { Cumprimento / } \\
\text { Realização }\end{array}$ & & $\begin{array}{l}\text { 1. O alojamento foi representado com precisão } \\
\text { pelo site. } \\
\text { 2. Este site cumpre as datas previamente } \\
\text { estabelecidas. } \\
\text { 3. O alojamento correspondeu ao esperado. }\end{array}$ \\
\hline & Agilidade na resposta & & $\begin{array}{l}\text { 1. Este site está disposto e pronto para responder } \\
\text { às necessidades dos consumidores. } \\
\text { 2. Neste site as perguntas são respondidas } \\
\text { prontamente. } \\
\text { 3. Quando tenho um problema, este site mostra } \\
\text { um sincero interesse em resolvê-lo. }\end{array}$ \\
\hline & $\begin{array}{c}\text { Segurança / } \\
\text { Privacidade do site }\end{array}$ & & $\begin{array}{l}\text { 1. Este site tem recursos de segurança } \\
\text { adequados. } \\
\text { 2. Eu sinto-me seguro nas minhas transações que } \\
\text { faço neste site. } \\
\text { 3. Eu sinto que a minha privacidade está } \\
\text { protegida neste site. }\end{array}$ \\
\hline
\end{tabular}

Observatório de Inovação do Turismo - Revista Acadêmica

Vol. XIV, $n^{\circ} 3$, dezembro - 2020 
DETERMINANTES DA LEALDADE ONLINE EM

SITES DE ALOJAMENTO: UM ESTUDO

COMPARATIVO DO COMPORTAMENTO DO

CONSUMIDOR PORTUGUÊS E BRASILEIRO
Pâmela Mossmann de Aguiar Cristela Maia Bairrada Arnaldo Fernandes Matos Coelho

\begin{tabular}{|c|c|l|}
\hline Variável & \multicolumn{1}{|c|}{ Autor } & \multicolumn{1}{|c|}{ Itens } \\
\hline Personalização & Kim et al (2011) & $\begin{array}{l}\text { 1. Os anúncios e promoções que este site me envia são } \\
\text { adaptados às minhas necessidades. } \\
\text { 2. Este site dá-me a impressão que eu sou um cliente } \\
\text { especial. } \\
\text { 3. Este site permite-me personalizar as minhas } \\
\text { necessidades. } \\
\text { 4. Sempre que possível, sinto que as minhas necessidades } \\
\text { são tidas em conta e respondidas de forma individual. } \\
\text { 5. Este site permite-me fazer reservas personalizadas. } \\
\text { 6. O feedback que dou sobre a qualidade dos bens e } \\
\text { serviços é altamente valorizado. }\end{array}$ \\
\hline
\end{tabular}

\begin{tabular}{|c|c|c|}
\hline Variável & Autor & Itens \\
\hline Aprendizagem & $\begin{array}{c}\text { Alnawas \& } \\
\text { Aburub (2016) }\end{array}$ & $\begin{array}{l}\text { 1. Este site ajuda-me a obter soluções para problemas } \\
\text { específicos relacionados com o uso do serviço. } \\
\text { 2. Este site estimula o meu pensamento sobre muitos } \\
\text { diferentes tópicos. } \\
\text { 3. Este site fornece informações que me ajudam a tomar } \\
\text { decisões importantes. } \\
\text { 4. Este site aumenta o meu conhecimento sobre o serviço } \\
\text { e o seu uso. } \\
\text { 5. Este site ajuda-me a gerir melhor o meu dinheiro. }\end{array}$ \\
\hline
\end{tabular}

\begin{tabular}{|c|c|l|}
\hline Variável & \multicolumn{1}{|c|}{ Autor } & \multicolumn{1}{|c|}{ Itens } \\
\hline Boca-a-boca & Liang (2015) & $\begin{array}{l}\text { 1. Os comentários de anteriores clientes aumentam o } \\
\text { valor deste site. } \\
\text { online recebido } \\
\text { minha intenção de efetuar uma reserva neste site. } \\
\text { 3. Os comentários de anteriores clientes diminuem a } \\
\text { minha perceção de risco. }\end{array}$ \\
\hline
\end{tabular}

Observatório de Inovação do Turismo - Revista Acadêmica

Vol. XIV, $n^{\circ} 3$, dezembro - 2020 
DETERMINANTES DA LEALDADE ONLINE EM

SITES DE ALOJAMENTO: UM ESTUDO

COMPARATIVO DO COMPORTAMENTO DO

CONSUMIDOR PORTUGUÊS E BRASILEIRO
Pâmela Mossmann de Aguiar Cristela Maia Bairrada Arnaldo Fernandes Matos Coelho

\begin{tabular}{|c|c|l|}
\hline Variável & Autor & \multicolumn{1}{c|}{ Itens } \\
\hline $\begin{array}{c}\text { Valor } \\
\text { hedônico }\end{array}$ & $\begin{array}{c}\text { Mouakket \& Al- } \\
\text { hawari (2012) }\end{array}$ & 2. Reservar online é excitante. \\
& 3. Reservar online é agradável. \\
& 4. Reservar online dá-me prazer. \\
\hline
\end{tabular}

\begin{tabular}{|c|c|l|}
\hline Variável & \multicolumn{1}{|c|}{ Autor } & \multicolumn{1}{c|}{ Itens } \\
\hline $\begin{array}{c}\text { Percepção } \\
\text { de valor }\end{array}$ & Li et al (2015) & $\begin{array}{l}\text { 1. Para os preços que eu pago neste site, eu diria que } \\
\text { fazer compras neste site é um bom negócio. } \\
\text { 2. Os serviços fornecidos por este site têm preços } \\
\text { razoáveis. } \\
\text { 3. Este site oferece um bom valor para o dinheiro pago. } \\
\text { 4. Os benefícios que eu recebo ao usar este site superam } \\
\text { significativamente os custos. }\end{array}$ \\
\hline
\end{tabular}

\begin{tabular}{|c|c|l|}
\hline Variável & \multicolumn{1}{|c|}{ Autor } & \multicolumn{1}{|c|}{ Itens } \\
\hline \multirow{2}{*}{$\begin{array}{c}\text { Valor } \\
\text { utilitário }\end{array}$} & $\begin{array}{l}\text { Mouakket \& Al- } \\
\text { hawari (2012) }\end{array}$ & $\begin{array}{l}\text { 1. Eu acho que reservar online é útil. } \\
\text { 2. Reservar online permite-me realizar a tarefa } \\
\text { 3apidamente. }\end{array}$ \\
& $\begin{array}{l}\text { 3. Reservar online torna o processo de reserva fácil. } \\
\text { 5. Reservar online permite-me realizar transações que } \\
\text { não estão próximas da minha localização. }\end{array}$ \\
\hline
\end{tabular}

\begin{tabular}{|c|c|l|}
\hline Variável & \multicolumn{1}{|c|}{ Autor } & \multicolumn{1}{c|}{ Itens } \\
\hline Percepção & Alcántara-Pilar \\
de risco & $\begin{array}{l}\text { 1. Há um baixo risco de perda se eu fizer uma reserva } \\
\text { através deste site. } \\
\text { 2. Há um baixo risco envolvido em fazer uma reserva } \\
\text { através deste site. } \\
\text { 3. Efetuar reservas de turismo através deste site não é } \\
\text { arriscado. }\end{array}$ \\
\hline
\end{tabular}

Observatório de Inovação do Turismo - Revista Acadêmica

Vol. XIV, n $^{\circ} 3$, dezembro - 2020 
DETERMINANTES DA LEALDADE ONLINE EM

SITES DE ALOJAMENTO: UM ESTUDO

COMPARATIVO DO COMPORTAMENTO DO

CONSUMIDOR PORTUGUÊS E BRASILEIRO
Pâmela Mossmann de Aguiar Cristela Maia Bairrada Arnaldo Fernandes Matos Coelho

\begin{tabular}{|c|c|l|}
\hline Variável & \multicolumn{1}{|c|}{ Autor } & \multicolumn{1}{c|}{ Itens } \\
\hline $\begin{array}{c}\text { Satisfação } \\
\text { online }\end{array}$ & $\begin{array}{c}\text { Gracia et al } \\
\text { (2015) }\end{array}$ & $\begin{array}{l}\text { 1. Com base na minha experiência com este site, eu sinto- } \\
\text { me muito satisfeito. } \\
\text { 2. Em geral, o meu relacionamento com este site satisfaz } \\
\text { as minhas expectativas. } \\
\text { 3. A minha relação com este site é próxima de ser } \\
\text { perfeita. } \\
\text { 4. Eu acho que fiz a coisa certa quando decidi usar este } \\
\text { site. }\end{array}$ \\
\hline
\end{tabular}

\begin{tabular}{|c|c|c|}
\hline Variável & Autor & Itens \\
\hline $\begin{array}{c}\text { Confiança } \\
\text { online }\end{array}$ & $\begin{array}{c}\text { Forgas et al } \\
\text { (2012) }\end{array}$ & $\begin{array}{l}\text { 1. A informação oferecida por este site é sincera e } \\
\text { honesta. } \\
\text { 2. Em geral, este site cumpre com os seus compromissos. } \\
\text { 3. Este site interessa-se pelas necessidades dos seus } \\
\text { clientes. } \\
\text { 4. Este site tem a capacidade técnica para fazer bem o seu } \\
\text { trabalho. }\end{array}$ \\
\hline
\end{tabular}

\begin{tabular}{|c|c|c|}
\hline Variável & Autor & Itens \\
\hline $\begin{array}{l}\text { Lealdade } \\
\text { online }\end{array}$ & $\begin{array}{c}\text { Audrain-Pontevia } \\
\text { et al (2013) }\end{array}$ & $\begin{array}{l}\text { 1. No futuro, eu provavelmente comprarei novamente } \\
\text { neste site. } \\
\text { 2. Se eu tivesse que fazer uma compra novamente, eu } \\
\text { selecionaria este site. } \\
\text { 3. Enquanto este site existir, acho que não vou mudar de } \\
\text { site. }\end{array}$ \\
\hline
\end{tabular}

\begin{tabular}{|c|c|l|}
\hline Variável & \multicolumn{1}{|c|}{ Autor } & \multicolumn{1}{c|}{ Itens } \\
\hline $\begin{array}{c}\text { Intenção de } \\
\text { troca }\end{array}$ & $\begin{array}{c}\text { Fuentes-Blasco } \\
\text { et al (2010) }\end{array}$ & $\begin{array}{l}\text { 1. Para mim, usar um novo site tem um alto custo em } \\
\text { tempo, dinheiro e esforço. }\end{array}$ \\
& $\begin{array}{l}\text { 2. Custar-me-ia muito trocar de site. } \\
\text { 3. Seria-me realmente inconveniente trocar para outro } \\
\text { site. }\end{array}$ \\
\hline
\end{tabular}

Fonte: Elaborado pelos autores.

Observatório de Inovação do Turismo - Revista Acadêmica

Vol. XIV, n $^{\circ} 3$, dezembro - 2020 